\title{
CHROMOSOME NUMBERS OF GAMMARIDS
}

\author{
By A. J. E. Orian and H. G. Callan, D.Sc. \\ Department of Natural History, The University, St Andrews
}

(Plate I and Text-figs. I-4)

The taxonomy of gammarid amphipods is a notoriously difficult subject. The group comprises a large number of recognized species whose identification depends on an expert knowledge of morphological minutiae. We began the study to be described in the present paper with the hope that a knowledge of the chromosome numbers of gammarids might be of taxonomic value. This hope has proved in the event to be largely ill-founded. We also undertook the present study in order to resolve a dispute as to whether polyploidy has played a part in gammarid evolution. This question has been clearly settled in the negative sense.

The nuclear cytology of most Crustacea presents severe technical problems. All crustaceans so far examined have relatively small, often extremely small, chromosomes. Most of the higher Crustacea have high chromosome numbers, those of decapods being the highest chromosome numbers in the whole animal kingdom. Gammarids, with small chromosomes and diploid numbers up in the fifties, are by no means easy cytological material.

From the literature describing previous work on gammarid cytology it was abundantly clear that we would make little progress using stained paraffin sections of testes of the various species. Aceto-carmine-stained squash preparations of gammarid testes have been used by the most reliable previous workers, but in our limited experience such preparations are frequently defective as regards quality of fixation and, critically and regularly, in the absence of analysable side views of first meiotic metaphase. Staiger \& Bocquet's paper demonstrating female heterogamety in certain isopods (Staiger \& Bocquet, I954) suggested to us that it might be more profitable to base our cytological study of gammarids on oocyte meiosis. By making squash preparations of oocytes just prior to oviposition Staiger \& Bocquet obtained analysable side views of first meiotic metaphase, and it is clear from their illustrations that the chromosomes of faera oocytes are considerably larger than those of spermatocytes. There are comparable advantages in studying oocyte as opposed to spermatocyte meiosis in the prosobranch gastropod Nucella lapillus (L.) (Staiger, 1954, as Purpura) and the earthworm Eisenia foetida (Savigny) (Callan, unpublished).

Previous determinations of the chromosome numbers of gammarids are listed by Le Calvez \& Certain (I95I). Their list, with minor modifications, is 
reproduced in Table I. Within this list the haploid numbers of I3 for Gammarus chevreuxi and G. duebeni, on the authority of Palmer and Le Roux, ${ }^{1}$ respectively, stand apart from all the other determinations, which range from $n=22$ to $n=27$. At first sight this incongruity might appear to indicate that G. chevreuxi and G. duebeni are diploid members of a predominantly tetraploid group. However, Le Calvez \& Certain (I95I) redetermined the chromosome numbers of G. chevreuxi and G. duebeni (specimens of the latter species from the same locality as those with which Mme Le Roux had previously worked),

TABLE 1. PUBLISHED CHROMOSOME NUMBERS OF GAMMARIDS

\section{Haploid}

Species

Gammarus chevreuxi Sexton

$G$. chevreuxi Sexton

$G$. chevreuxi Sexton

$G$. duebeni Lilljeborg

$G$. duebeni Lilljeborg

G. zaddachi Sexton

G. pulex pulex (L.)

$G$. locusta (L.)

G. pungens Milne Edwards

$G$. annandalei Tattersall

Marinogammarus marinus (Leach)

Echinogammarus berilloni (Catta)

Carinogammarus roeseli (Gervais)

Niphargus plateaui var. elongatus Chevreux

N. tatrensis var. lunzensis Schell.

Melita palmata (Montagu)

Maera othonis (Milne Edwards)

M. grossimana (Montagu)

Metacrangonyx longipes Chevreux number

ca. 22

13

26

13

27

26

26

26

24

27

26

26

26

25

25

22

23

23

* In all probability Le Roux's species was really Gammarus z. zaddachi.

$\dagger$. zaddachi was incorrectly designated G. duebeni in Le Calvez's I949 paper: the error was corrected in the I95I paper by Le Calvez \& Certain.

and found haploid numbers of 26 and 27 . With considerable justification they suggested that both Palmer's and Le Roux's determinations were based on inadequate techniques and were erroneous. Nevertheless, some uncertainty still remained: Palmer's $G$. chevreuxi material originated from Plymouth, whereas Le Calvez \& Certain's G. chevreuxi came from Roscoff, and thus the alternative chromosome numbers might conceivably reflect genuine interracial differences.

By working with oocytes we have been able to make accurate chromosome counts in nine gammarid species. However, since in at least three of these species chromosome number varies from individual to individual, and since the chromosome numbers of different species overlap, it is clear that chromosome counts will not be of great value to students of gammarid systematics.

1 According to G. M. Spooner (personal communication) the illustrations and comparative measurements of limbs given in Le Roux's paper indicate that she was dealing with the typical subspecies of Gammarus zaddachi Sexton and not with G. duebeni. 
Reliance can be placed on the identification of material which we have studied cytologically since we have enjoyed the invaluable assistance of two experts on gammarid taxonomy, Dr C. Edwards of the Scottish Marine Biological Association at Millport, and Mr G. M. Spooner of the Marine Biological Association of the United Kingdom at Plymouth.

\section{MATERIALS AND METHODS}

We started our cytological work on gammarids by making aceto-orcein squash preparations of fresh and of acetic-alcohol prefixed testes of several species. In well-flattened preparations equatorial plates of first meiotic metaphase are only to be seen in polar view: the bivalents are crowded so close together (the first metaphase equatorial plates of G. chevreuxi, G. locusta and of Marinogammarus marinus are only some 7 or $8 \mu$ in diameter) that it proved quite impossible to make accurate chromosome counts. At second meiotic metaphase the difficulties are still greater: in Gammarus chevreuxi, for example, the diameter of a second metaphase equatorial plate is only some 4-5 $\mu$. Occasional spermatogonial prometaphases can be counted with fair accuracy, but in most preparations these are not sufficiently frequent to allow of adequate cross-checking. In short, we would not have been able to establish with certainty the existence of chromosomal polymorphism in gammarid species by working with testis preparations alone.

In order to work on oocyte meiosis it is necessary to know the state of maturation of the eggs relative to the macroscopic cycle of events connected with oviposition. As is well-known, male and female gammarids associate in precopula several days before egg-laying. The female moults, and immediately thereafter the male turns the female round so that the pair lie transverse to one another: the male then ejects sperm into the female's brood-chamber. The pre-oviposition moult is an event which can be readily observed and it forms a useful reference point within the maturation cycle. Thirty to ninety minutes after the moult, dependent on species and on temperature, the first eggs drop down the paired oviducts into the brood-pouch. In pale species with wellpigmented eggs, e.g. Marinogammarus pirloti, this event can also be readily observed. The eggs collect in the brood-pouch in two thin-walled transient structures, the so-called 'mucous sacs', which slowly dissolve and disappear completely some $2 \mathrm{hr}$ later: sperm penetration takes place at this time.

We have established the time-scale of the cytological events taking place during maturation of the eggs in Gammarus pulex L., the animals being maintained in good conditions at a constant temperature of $15^{\circ} \mathrm{C}$. This time-scale is shown in Table 2.

Chromosome numbers can be established with certainty at three stages: first and second meiotic metaphase, and first cleavage metaphase (later cleavage metaphases are also of value, though they become progressively 
more difficult to analyze the older the embryo). Typical photographs of these three stages are shown in Pl. I, figs. 2-5; for the sake of comparison a photograph of a particularly clear G. pulex spermatocyte first meiotic metaphase is also included in this plate (fig. I). The great superiority of the egg preparations is evident. Of these three stages, oocyte first meiotic metaphase is the most informative: unfortunately it presents greater technical difficulties than do second meiotic metaphase or first cleavage mitosis in that the eggs in oviduct and ovary are very fragile, they stick together and cannot be entirely freed from ovarian wall tissue, and the stage is of short duration. We have intentionally worked with first meiotic metaphase only in G. pulex (first meiotic metaphase of Marinogammarus marinus was obtained by accident). Studies on the other species have been confined to second meiotic metaphase, in several respects the most easy stage with which to work.

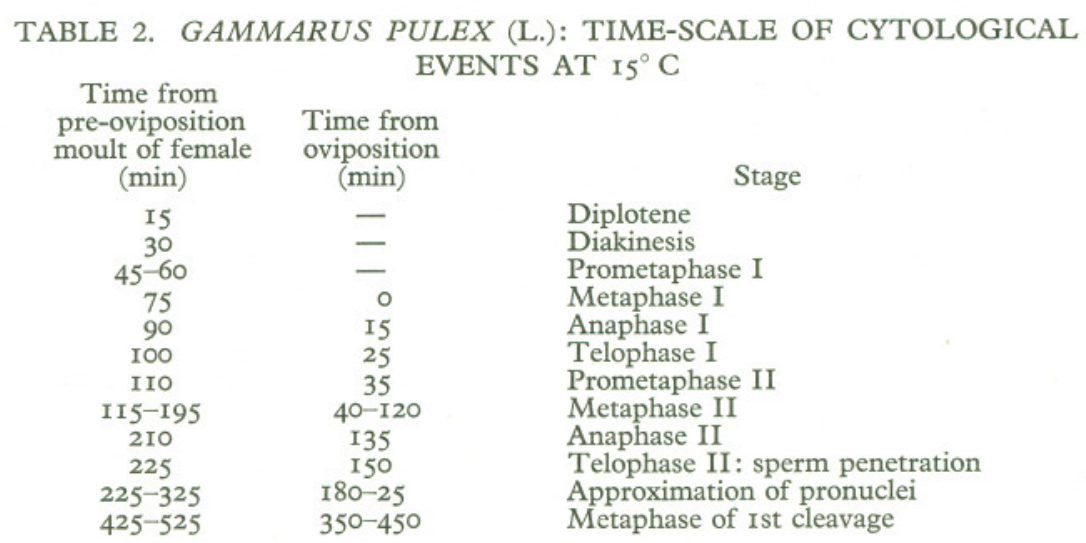

For preparations of first meiotic metaphase in Gammarus pulex isolated pairs in precopula were watched for moulting. Sixty to ninety minutes after moulting the female was removed, slit open along its dorsal side and fixed entire in Carnoy's fluid (three parts absolute alcohol:one part glacial acetic acid). Soon thereafter the ovaries and oviducts were dissected out and transferred to fresh Carnoy's fixative for $\mathrm{I} 2-\mathrm{I} 8 \mathrm{~h}$.

For preparations of second meiotic metaphase in all species maintained at a temperature of $15^{\circ} \mathrm{C}$. the coupled pairs were watched for moulting and for the subsequent start of oviposition. Two hours after the beginning of oviposition the eggs were dissected out from the brood pouch and mucous sacs, washed in sea or tap water as appropriate, fixed in Carnoy's fluid, transferred to fresh fixative a few minutes later, and left for $\mathrm{I} 2 \mathrm{2}-\mathrm{I} 8 \mathrm{~h}$. For preparations of embryonic mitoses the embryos were similarly treated, being however allowed to remain for longer periods in the female's brood pouch prior to fixation.

After fixation the ovaries, eggs or embryos were transferred with as little fixative as possible to a freshly filtered I \% orcein solution made up in $45 \%$ 
acetic acid and there left to stain for 4-6 h. Natural orcein gave us considerable trouble since it forms a noticeable precipitate within a few hours. Synthetic orcein supplied by G. T. Gurr later proved to be much superior both in staining qualities and freedom from precipitate.

The stained material was arranged on a clean coverslip over which an albuminized slide was subsequently lowered. Between folded filter-papers slide and coverslip were squashed very firmly together, and the edges of the coverslip then sealed with paraffin wax.

Most of the observations were made on such temporary preparations, which keep in good condition for several weeks if stored in a refrigerator just above freezing-point. Valuable preparations were later made permanent. The wax was soaked off in xylol and the preparation inverted in a ridged dish containing $90 \%$ alcohol. After a day or two in $90 \%$ alcohol such coverslips as had not separated freely from their slides were prized off with a razor blade. The material generally remained attached to the albuminized slide, which was then dehydrated in absolute alcohol and mounted in Euparal.

\section{Gammarus pulex (L.)}

Although we did not start our study of gammarid chromosomes with the freshwater Gammarus pulex, it is convenient to deal with this species first. Our material was supplied by the Freshwater Biological Association, Ambleside.

Chromosome numbers found in oocytes at second meiotic metaphase are shown in Table III. From this table it will be seen that five females produced oocytes each containing 26 chromosomes, two females produced equal numbers of oocytes with 26 or 27 chromosomes, and one female produced oocytes each containing 27 chromosomes. Characteristic second meiotic metaphase chromosome groups, one with 26 and the other with 27 chromosomes, are shown in Text-fig. I and in Pl. I, figs. 3 and 4.

These observations suggested that $G$. pulex may have alternative diploid chromosome numbers of 52,53 or 54 . Our attention was now directed towards mitotic divisions in embryos. The existence of 52- and 53-type embryos was confirmed, though no 54-type was encountered amongst forty-four embryos from twelve females. 53-type embryos were present amongst the egg-batches of five different females, but since we do not know whether any of these egg-batches were uniformly of 53-type the chromosome constitutions of the parents, male or female, cannot be certainly stated.

We next examined first meiotic metaphase in oocytes, and for this purpose fixed the ovaries of some eighty females at the appropriate stage. Amongst these females six were definitely established as 53-type and three as 54-type. The majority of the remaining females were certainly 52 -type, but the absolute ratio is not worth quoting since the constitution of too many animals within the group could not be definitely established. 
In 52 -type females the oocytes regularly show 26 bivalents: $G$. pulex chromosomes have median or submedian centromeres, and most of the bivalents appear to be associated by single chiasmata in both arm pairs (P1. I, fig. 2; Text-fig. $2 a, b$ ). In 53-type females the oocytes regularly show 26 bivalents and a single univalent (Text-fig. $2 c, d$ ). Trivalent associations were not observed in any of the sixty-two cells of this type which were fully analysed. In 54-type females the oocytes generally show 27 bivalents (Text-fig. $2 c, f$ ),
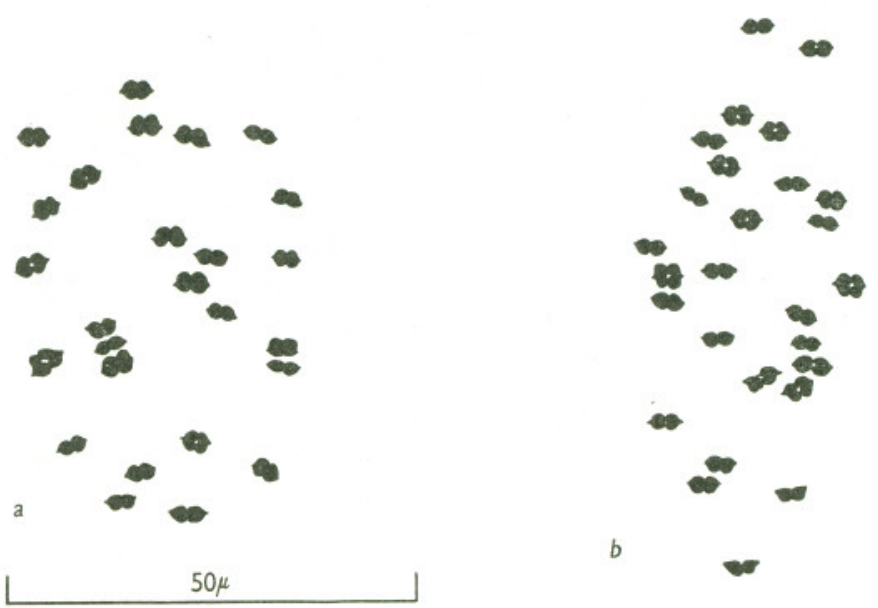

Text-fig. I. Camera lucida drawings of second meiotic metaphase chromosome groups from oocytes of Gammarus pulex: (a) with 26 and (b) with 27 chromosomes.

\begin{tabular}{|c|c|c|c|}
\hline \multirow{2}{*}{$\begin{array}{l}\text { Specimen } \\
\text { number }\end{array}$} & \multicolumn{2}{|c|}{$\begin{array}{l}\text { Number of secondary oocytes } \\
\text { with chromosome numbers of }\end{array}$} & \multirow{2}{*}{$\begin{array}{l}\text { Assessed } \\
\text { diploid } \\
\text { chromosome } \\
\text { number }\end{array}$} \\
\hline & 26 & 27 & \\
\hline 5 & 8 & IO & 53 \\
\hline 7 & I 2 & - & 52 \\
\hline 9 & - & I6 & 54 \\
\hline IO & 6 & 7 & 53 \\
\hline I I & 8 & - & 52 \\
\hline I2 & 6 & - & 52 \\
\hline I5 & 5 & - & 52 \\
\hline 29 & 5 & - & 52 \\
\hline
\end{tabular}

though in four cells out of the twenty-seven of this type which were fully analyzed there was some uncertainty as to the status of one pair of chromosomes, which had either disioined precociously or, less probably, which had failed to associate earlier in meiosis. No multivalent chromosome associations were observed in oocytes from 54-type females.

To judge from the chromosome counts made at second meiotic metaphase, chromosome disjunction at first anaphase is regular in 52- and 54-type oocytes, 
whilst in 53-type oocytes the univalent appears normally to pass undivided into secondary oocyte or polar body with equal frequency. The picture is complicated, however, by the occasional presence in 52- 53- or 54-type females of minute fragment chromosomes which, at least on occasion, lag

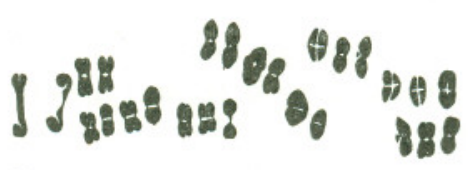

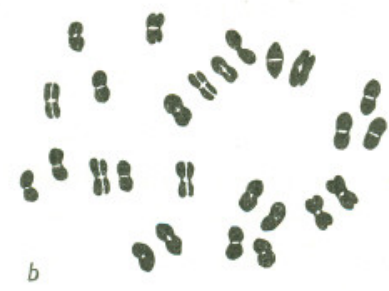
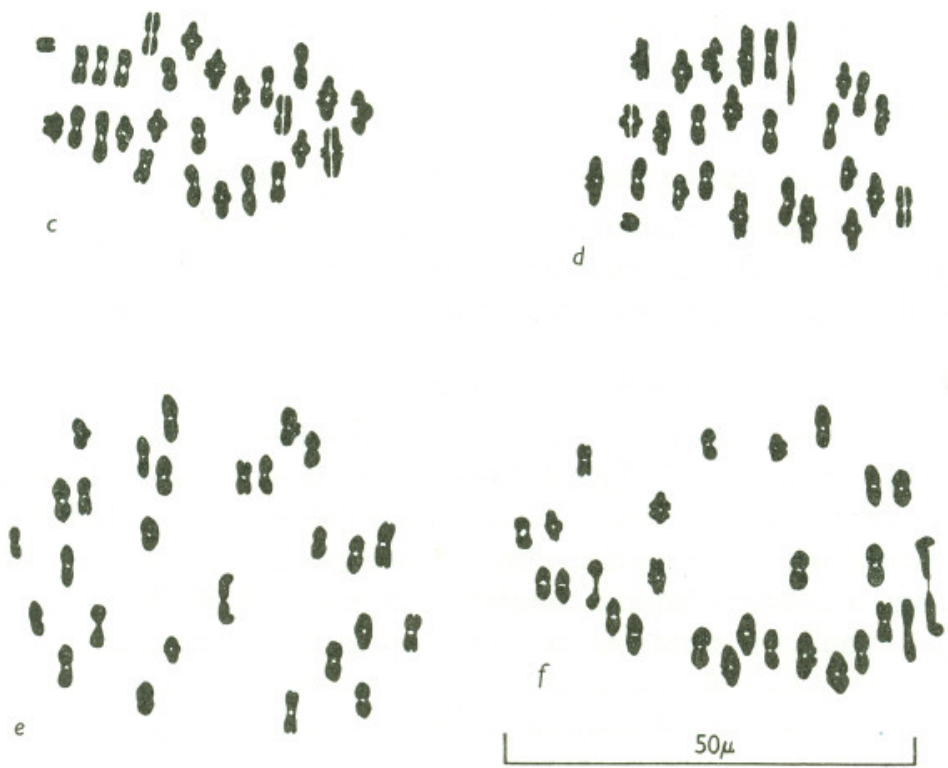

Text-fig. 2. Camera lucida drawings of first meiotic metaphase chromosome groups from oocytes of Gammarus pulex: (a) and (b) with 26 bivalents; $(c)$ and $(d)$ with 26 bivalents plus one univalent (top left in $c$, bottom left in $d$ ); $(e)$ and $(f)$ with 27 bivalents.

behind on the equator at first anaphase. We do not know the fate of such fragment chromosomes nor their relationship to the chromosomes of the regular complement. They are not the outcome of crossing-over within inversion heterozygotes since they are not accompanied by bridges and, when present, are to be seen in every oocyte of a particular female.

The chromosomes of $G$. pulex are considerably larger than those of the other gammarids which we have studied and from a cytological standpoint 
this is not a difficult species with which to work. It would be of interest to study the chromosome constitutions of different populations of G. pulex and also to determine whether, since in this animal several generations succeed one another within the year, there is any seasonal variation in chromosome constitution within a given population.

\section{Gammarus duebeni Lilljeborg}

A few oocytes from four examples of this species collected at the East Rocks, St Andrews, gave chromosome counts of 27 at second meiotic metaphase. This number agrees with the determination of Le Calvez \& Certain (195I) and it corroborates their suggestion that Madame Le Roux's determination was erroneous.

\section{Gammarus locusta (L.)}

A few oocytes from six examples of this species supplied by the Dove Marine Laboratory, Cullercoats, gave chromosome counts of 26 at second meiotic metaphase. This number agrees with the determination of Poisson \& Le Calvez (1948).

Gammarus zaddachi Sexton subsp. salinus Spooner

A few oocytes from two examples of this species collected at the East Rocks, St Andrews, gave chromosome counts of 26 at second meiotic metaphase. This number again agrees with the determination of Le Calvez (1949).

\section{Gammarus chevreuxi Sexton}

Specimens of G. chevreuxi from Chelson Meadow, Plym Estuary, were supplied by the Marine Biological Association's laboratory at Plymouth and were thus from the same site as those which Palmer (1926) studied. Forty oocyte second meiotic metaphase chromosome groups from ten females were counted and a constant haploid number of 26 established. As can be seen in Text-fig. $3 a$ and $b$, the chromosomes of $G$. chevreuxi are very small indeed. The determination of Le Calvez \& Certain (I95I) has been corroborated, and their suggestion that Palmer's determination was erroneous upheld.

\section{Marinogammarus obtusatus (Dahl)}

This species was collected at the East Rocks, St Andrews. Eighty-nine oocyte second meiotic metaphase chromosome groups from fifteen females were counted and a constant haploid number of 26 established. (See Pl. I, fig. 6; Text-fig. $3 c, d$ ).

\section{Marinogammarus finmarchicus (Dahl)}

This species was collected at the East Rocks, St Andrews. Twenty-two oocyte second meiotic metaphase chromosome groups from four females each gave counts of 26 (see Text-fig. $3 e, f$ ). 

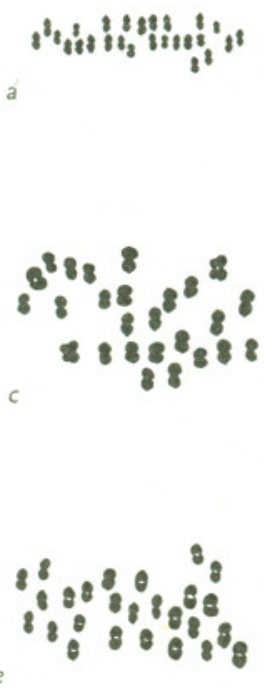
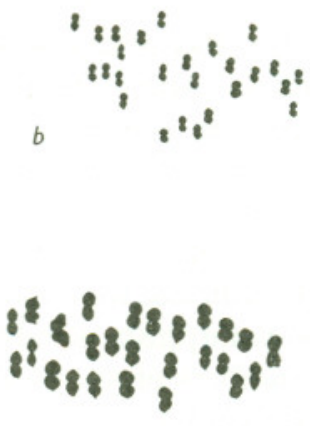

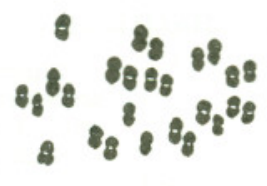

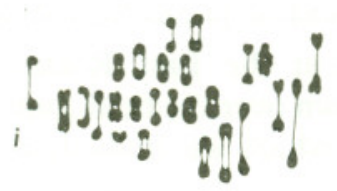

Text-fig. 3. (a) and (b) second meiotic metaphase chromosome groups from oocytes of Gammarus chevreuxi, both with 26 chromosomes. (c) and (d) second meiotic metaphase chromosome groups from oocytes of Marinogammarus obtusatus, both with 26 chromosomes. $(e)$ and $(f)$ second meiotic metaphase chromosome groups from oocytes of $M$. finmarchicus. both with 26 chromosomes. $(g)$ and $(h)$ second meiotic metaphase chromosome groups from oocytes of M. marinus, $(g)$ with 25 and $(h)$ with 26 chromosomes. (i) first meiotic metaphase chromosome group from oocyte of Marinogammarus marinus with 25 bivalents plus one univalent. All same magnification as Text-fig. I. 
Marinogammarus marinus (Leach)

This species was collected at the East Rocks, Eden Estuary and Harbour, St Andrews. Apart from one exceptional observation on a delayed first metaphase, the chromosomes of this species were studied at first meiotic anaphase and second meiotic metaphase: the counts are listed in Table 4.

The chromosomes of $M$. marinus (Text-fig. $3 g, h$ ) are nearly as small as those of $G$. chevreuxi, and a great many preparations could not be analysed. However, sufficient were scored to establish that this species shows a chromosomal polymorphism similar to that of $G$. pulex, though with alternative diploid numbers of 50,51 and 52. By good fortune specimen 33 contained one oocyte with a delayed and well-spread first meiotic metaphase, and this preparation showed 25 bivalents plus one univalent (Text-fig. $3 i$ ). Of the ten females studied four were 50-type, five were 51-type and one 52-type.

TABLE 4. CHROMOSOMES OF MARINOGAMMARUS MARINUS (LEACH)

\begin{tabular}{|c|c|c|c|c|c|}
\hline \multirow{2}{*}{$\begin{array}{c}\text { Specimen } \\
\text { number }\end{array}$} & \multicolumn{2}{|c|}{$\begin{array}{c}\text { Numbers of } \\
\text { secondary oocytes } \\
\text { with chromosome } \\
\text { numbers of }\end{array}$} & \multicolumn{2}{|c|}{$\begin{array}{l}\text { Numbers of first polar } \\
\text { bodies with chromo- } \\
\text { some numbers of }\end{array}$} & \multirow{2}{*}{$\begin{array}{l}\text { Assessed } \\
\text { diploid } \\
\text { chromo- } \\
\text { some } \\
\text { number }\end{array}$} \\
\hline & 25 & 26 & 25 & 26 & \\
\hline 5 & - & IO & - & - & 52 \\
\hline 23 & 3 & 3 & - & - & $5 \mathrm{I}$ \\
\hline 33 & I & 2 & 2 & I & $5 I$ \\
\hline 36 & I & I & I & I & 51 \\
\hline 38 & 2 & 3 & - & - & 51 \\
\hline 39 & 5 & - & 5 & - & 50 \\
\hline 40 & 2 & 2 & - & - & $5 I$ \\
\hline $4 I$ & 3 & - & - & - & $50 ?$ \\
\hline 43 & 2 & 5 & - & - & $5 \mathrm{I}$ \\
\hline 44 & Io & - & - & - & 50 \\
\hline
\end{tabular}

Marinogammarus pirloti Sexton \& Spooner

This species was collected at the East Rocks, St Andrews, in a region where fresh water drains down over the tidal zone. M. pirloti happened to be the first gammarid species which we studied, and it presents a cytological problem of some complexity.

By virtue of the pale coloration of the females and the intense brown or black pigmentation of the eggs, the species provides admirable material for following the cycle of events at reproduction. Unfortunately, however, its chromosomes are as small as those of $M$. marinus, and there are more of them (Text-fig. 4). Counts were made at second meiotic metaphase in secondary oocytes (P1. I, figs. 7, 8), and the species is exceptional in that at this stage the polar body chromosomes are still condensed and also frequently countable. The counts are summarized in Table 5, numbers in brackets being counts made on polar body chromosome groups. It will be seen that in the six individuals studied haploid numbers range from 29 to 32 and assessed diploid 
numbers from 59 to (?) 63. The assessed diploid numbers could only be established when complementary oocyte and polar body chromosome groups were both countable (Text-fig. $4 a, b$ ), and even in such cases there were sometimes grounds for uncertainty. To judge from the appearance of some second meiotic metaphase chromosome groups, notably two of 32 in specimen I5 and one of 32 in specimen 19, chromosomes present as univalents during first meiosis may on occasion divide equationally at first anaphase. The normal second metaphase chromosomes are dumb-bell shaped, the constriction

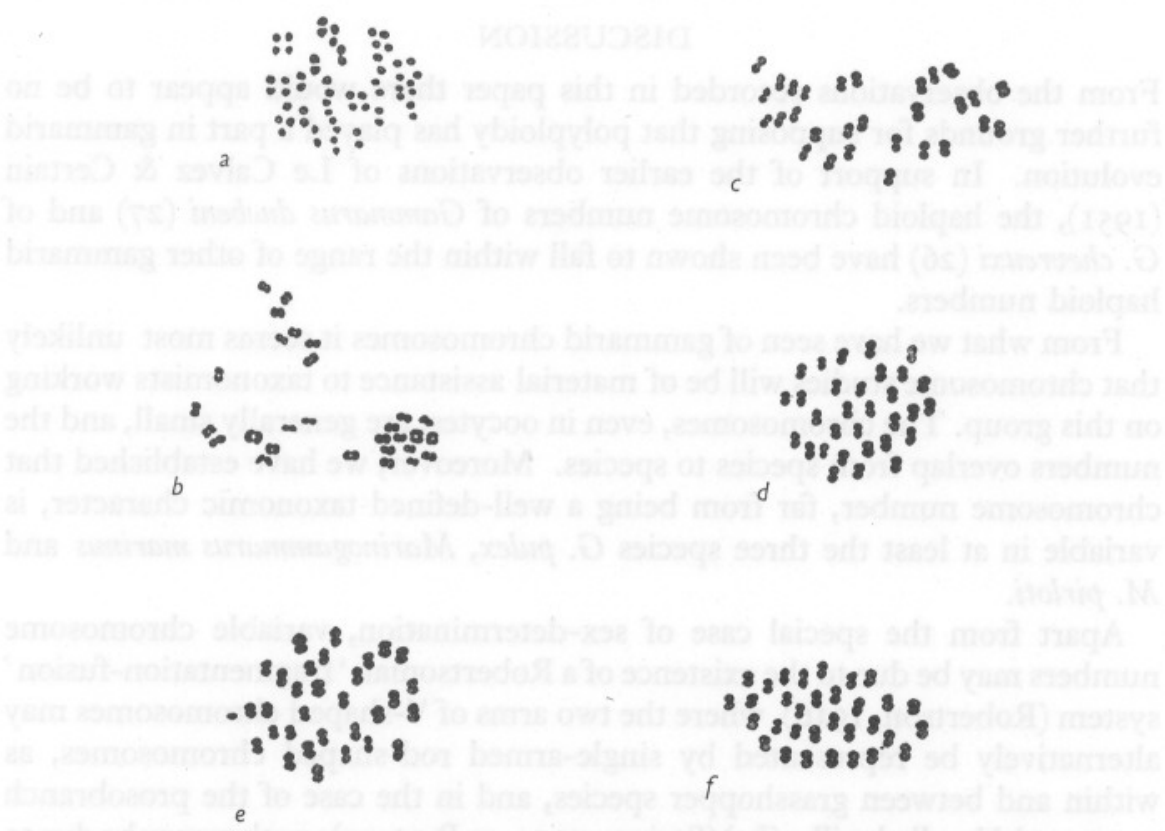

Text-fig. 4. (a) Early second meiotic anaphase and (b) first polar body chromosome groups from oocytes of Marinogammarus pirloti: (a) with $30 \times 2$ chromosomes; $(b)$ with 29 chromosomes. $(c),(d),(e)$ and $(f)$ second meiotic metaphase chromosome groups from oocytes of $M$. pirloti: (c) with 29 chromosomes; $(d)$ with 31 chromosomes; (e) with 32 chromosomes, the one on the extreme left being the product of the equational division of a univalent during first meiosis; $(f)$ with 32 chromosomes. All same magnification as Text-fig. I.

TABLE 5. CHROMOSOMES OF MARINOGAMMARUS PIRLOTI SEXTON \& SPOONER

Numbers of secondary oocytes (or Ist polar bodies) Assessed with chromosome numbers of diploid

\begin{tabular}{|c|c|c|c|c|c|}
\hline \multirow{2}{*}{$\begin{array}{l}\text { Specimen } \\
\text { number }\end{array}$} & \multicolumn{4}{|c|}{ with chromosome numbers of } & \multirow{2}{*}{$\begin{array}{l}\text { diploid } \\
\text { chromosome } \\
\text { number }\end{array}$} \\
\hline & 29 & 30 & $3 I$ & 32 & \\
\hline I & - & 2 & I & - & $6 \mathrm{I} ?$ \\
\hline 2 & - & 2 & $2(I)$ & - & $6 \mathrm{I}$ \\
\hline 3 & $5(2)$ & $6(2)$ & - & 一 & 59 \\
\hline 15 & - & I & - & $3(\mathrm{I})$ & 62 \\
\hline 18 & - & - & & & $63 ?$ \\
\hline I9 & 2 & $2(\mathrm{I})$ & $2(I)$ & $2(\mathrm{I})$ & $6 \mathrm{I}$ \\
\hline
\end{tabular}


marking the centromere: it is suggested that the small chromosome lacking a constriction shown in P1. I, fig. 8 , and in Text-fig. $4 e$, is the product of such an equational division.

It would clearly be of interest to work on the first meiotic division of $M$. pirloti and to carry out a much more extensive cytological survey. The species unquestionably shows chromosomal polymorphism, and higher chromosome numbers than any previously recorded for gammarids.

\section{DISCUSSION}

From the observations recorded in this paper there would appear to be no further grounds for supposing that polyploidy has played a part in gammarid evolution. In support of the earlier observations of Le Calvez \& Certain (I95I), the haploid chromosome numbers of Gammarus duebeni (27) and of G. chevreuxi (26) have been shown to fall within the range of other gammarid haploid numbers.

From what we have seen of gammarid chromosomes it seems most unlikely that chromosome studies will be of material assistance to taxonomists working on this group. The chromosomes, even in oocytes, are generally small, and the numbers overlap from species to species. Moreover, we have established that chromosome number, far from being a well-defined taxonomic character, is variable in at least the three species G. pulex, Marinogammarus marinus and M. pirloti.

Apart from the special case of sex-determination, variable chromosome numbers may be due to the existence of a Robertsonian 'fragmentation-fusion' system (Robertson, I9I6), where the two arms of $V$-shaped chromosomes may alternatively be represented by single-armed rod-shaped chromosomes, as within and between grasshopper species, and in the case of the prosobranch gastropod Nucella lapillus (L.) (Staiger, I954, as Purpura); or they may be due to the presence of supernumeraries extra to a basic complement. The variable chromosome numbers of gammarids do not appear directly related to a sexdetermining mechanism, though it is certainly conceivable that they may in some fashion be indirectly related. Clear proof of a Robertsonian system in gammarids is also wanting. In such a system the heterozygotes generally show trivalents at first meiosis where V-shaped chromosomes are associated with their genetically related two rod-shaped chromosomes, and indeed balanced disjunction within such a system is only possible when in heterozygotes trivalent associations are formed with great regularity. No multivalent associations were observed throughout our reasonably extensive studies on Gammarus pulex.

It is therefore reasonable to assume that the variable chromosome numbers of gammarids are due to the presence of supernumeraries, and that crustaceans should be added to the already long list of organisms in which such chromosomes have been found (see White, I954, p. I67). The genetic significance of 
supernumerary chromosomes remains to a great extent undecided, and light might well be thrown upon this problem by further work on the easily reared and cytologically manageable $G$. pulex.

\section{SUMMARY}

The chromosomes of nine species of gammarids have been studied in oocytes and embryos. There is no evidence that polyploidy has played a part in gammarid evolution. Three of the species which we have studied, Gammarus pulex (L.), Marinogammarus marinus (Leach) and M. pirloti (Sexton \& Spooner) show chromosomal polymorphism. There is no evidence that this polymorphism depends on the existence of a Robertsonian 'fragmentationfusion' system; rather it appears to be due to the presence of supernumerary chromosomes.

\section{REFERENCES}

HuXLEY, J. S., 1923. Further data on linkage in Gammarus chevreuxi, and its relation to cytology. F. exp. Biol., Vol. I, pp. 79-96.

Le CalveZ, J., 1949. Quelques nouveaux caryotypes de Crustacés Amphipodes. C.R. Acad. Sci., Paris, T. 228, pp. 427-428.

Le Calvez, J. \& Certain, P., I95I. Gammarus chevreuxi Sext. et la caryologie des Gammariens. Arch. Zool. exp. gén., T. 88, pp. 13I-I4I.

Le Roux, M. L., I933. Recherches sur la sexualité des Gammariens. Bull. Biol., Suppl., Vol. 16, 138 pp..

Niryama, H., I935. The chromosomes of Paralithodes camtschatica and Gammarus annandalei. Fap. F. Genet., Vol. II, pp. 34-35.

PALMER, R., I926. The chromosome complex of Gammarus chevreuxi Sexton. I. Spermatogenesis. Quart. F. micr. Sci., Vol. 70, pp. 54I-55I.

Poisson, R. \& Le CAlvez, J., 1948. La garniture chromosomique de quelques Crustacés Amphipodes. C.R. Acad. Sci., Paris, T. 227, pp. 228-230.

Robertson, W. R. B., I9I6. Chromosome studies. I. Taxonomic relationships shown in the chromosomes of Tettigidae and Acrididae. V-shaped chromosomes and their significance in Acrididae, Locustidae and Gryllidae: chromosomes and variation. F. Morph., Vol. 27, pp. I79-331.

Staiger, H., I954. Der Chromosomendimorphismus beim Prosobranchier Purpura lapillus in Beziehung zur Ökologie der Art. Chromosoma, Bd. 6, pp. 419-478.

STAIGER, H. \& BoCQUET, CH., I954. Cytological demonstration of female heterogamety in isopods. Experientia, T. 10, pp. 64-66.

White, M. J. D., I954. Animal Cytology and Evolution. Cambridge University Press. 


\section{EXPLANATION OF PLATE I}

Photomicrographs of 'squash' preparations stained in aceto-orcein: all figures at the same magnification.

Fig. I. Polar view of first meiotic metaphase in spermatocyte of Gammarus pulex.

Fig. 2. Side view of first meiotic metaphase in oocyte of $G$. pulex: 26 bivalents.

Fig. 3. Side view of second meiotic metaphase in oocyte of $G$. pulex: 26 chromosomes.

Fig. 4. Side view of second meiotic metaphase in oocyte of G. pulex: 27 chromosomes.

Fig. 5. Prometaphase of first mitotic division in fertilized egg of G. pulex: 52 chromosomes.

Fig. 6. Side view of second meiotic metaphase in oocyte of Marinogammarus obtusatus: 26 chromosomes.

Fig. 7. Side view of second meiotic metaphase in oocyte of $M$. pirloti: 29 chromosomes.

Fig. 8. Side view of second meiotic metaphase in oocyte of $M$. pirloti: 32 chromosomes, of which the one on the extreme right is the product of the equational division of a univalent during first meiosis. 

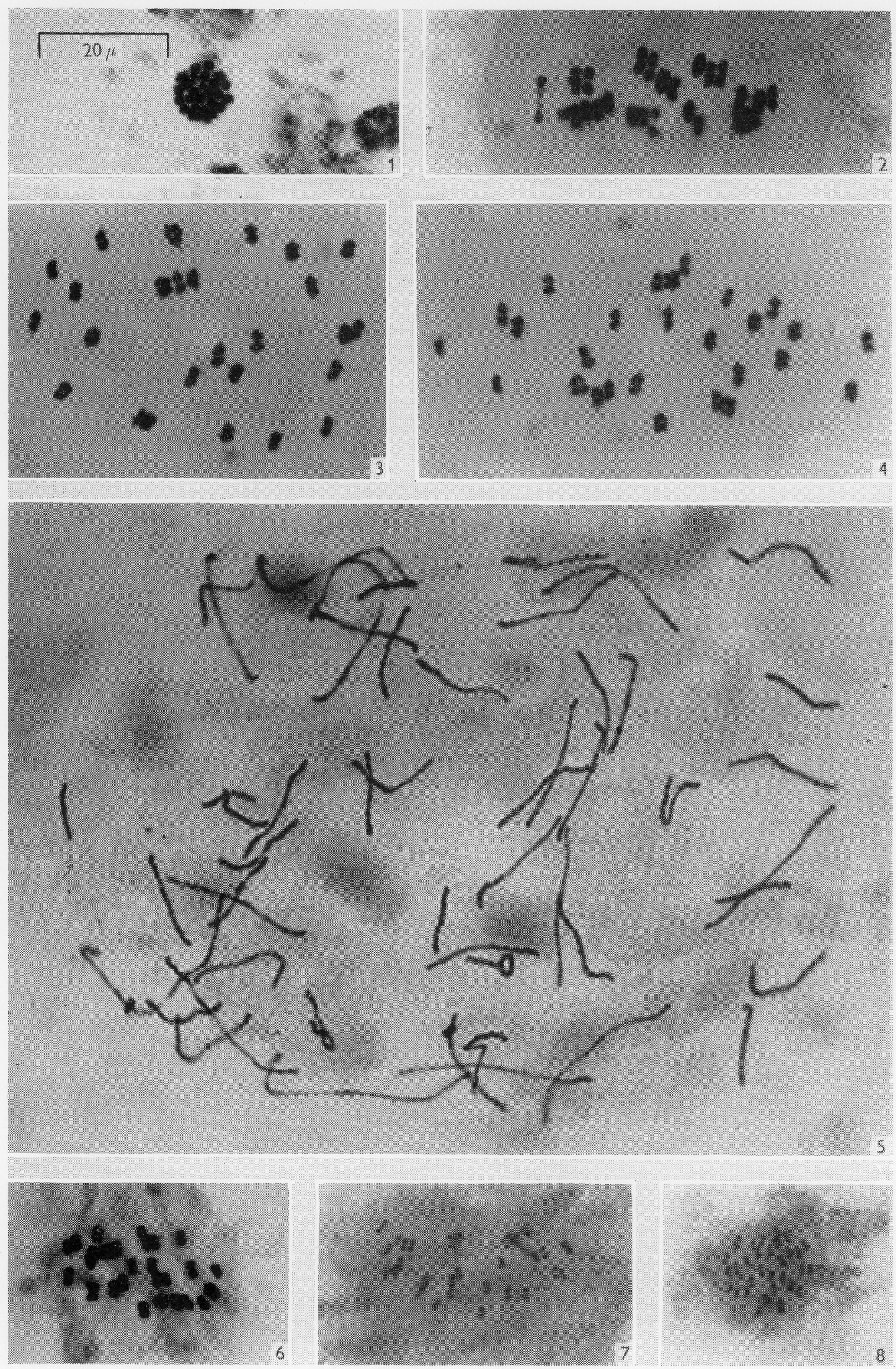

(Facing p. I42) 